\title{
Erythema elevatum diutinum and hypothyroidism: coincidence or causal relationship?*
}

\author{
Denise Camargo Cirvidiu ${ }^{1}$ \\ Juliana Chaib Ferraira Jorge ${ }^{1}$ \\ Samuel Henrique Mandelbaum
}

\author{
Beatriz Lopes Ferraz Elias ${ }^{1}$ \\ Márcia Lanzoni de Alvarenga Lira ${ }^{1}$
}

DOI: http:/ / dx.doi.org/ 10.1590/ abd1806-4841.20153284

\begin{abstract}
Erythema elevatum diutinum is a rare chronic leukocytoclastic vasculitis of unknown etiology. It is believed to be due to deposition of immune complexes in the vessels. Clinically it is manifested as erythematous violaceous papules and nodules, isolated or confluent with hardened consistency, symmetrical, usually located on the extensor surface of the extremities, particularly over the joints. Diagnosis is based on clinical and histological findings. We report the case of a woman, 71 years old, with erythematous violaceous nodules on the hands, el bows, back and legs, beginning two years ago, with pain and itching. Histopathological analysis reveal ed leukocytoclastic vasculitis, confirming the clinical suspicion. Laboratory tests revealed hypothyroidism. We report the case because of its rarity, with subsequent review of the literature.
\end{abstract}

Keywords: Dapsone; Erythema; Hypothyroidism; Vasculitis, leukocytoclastic, cutaneous

\section{INIRODUCTION}

The erythema elevatum diutinum (EED) is a rare chronic leukocytoclastic vasculitis of unknown etiology, characterized by the absence of systemic vasculopathy. ${ }^{1}$ It was first described by Hutchinson in 1878 and by Bury in 1889. Its name was given by Radcliffe-Crocker and Williams in 1894.1,2,3 Clinically it is manifested by erythematous violaceous papules and nodules, isolated or confluent, in hardened, symmetrical plaques predominantly on the extensor surface of extremities, mainly over the joins. The diagnosis is based on clinical and histological findings. In view of its rarity, a caseof EED and hypothyreoidism is here reported.

\section{CASE REPORT}

The case of a 71-year-old woman is reported. She presented erythematous violaceous papules on the back and buttocks; hardened, symmetrical erythematous violaceous nodules, some ulcerated, on the elbows, hands and feet; and ulcerated malleolar tumoral lesion for two years, accompanied by pain and pruritus (Figures 1 to 3). The patient mentioned progressive increase of lesions. The histopathological examination evidenced intense dermal neutrophilic infiltrate, diffuse and permeating vessel walls, which showed fibrinoid alterations and occasional leukocytoclasia, compatible with leukocytoclastic vasculitis (Figure 4). Laboratory investigation included complete blood count, renal, hepatic and thyroid function, protein electrophoresis, serologies for syphilis, HIV and hepatitides, rheumatoid factor, antinuclear antibody, glycemia, P-ANCA and C-ANCA, all without abnormal results except for TSH and free T4, compatible with hypothyreoidism and high levels of anti-thyroglobulin and anti-peroxidase antibodies. Abdominal and transvaginal ultrasound, colonoscopy and X-ray of the thorax and long bones had normal results. The data revealed in the tests confirmed the EED diagnosis and the treatment was begun with dapsone, intralesional corticosteroids and levothyroxine. The patient is being followed and presents unsatisfactory response to therapy.

Received on 24.11.2013.

A pproved by theAdvisory Board and accepted for publication on 19.01.2014.

* Study carried out at the Teaching Hospital of Taubaté - Universidade de Taubaté (HUT-UNITAU) - Taubaté (SP) - Brazil

Financial Support: None.

Conflict of Interest: None.

1 Universidade de Taubaté (UNITAU) - Taubaté (SP), Brazil.

(C2015 by A nais Brasileiros de Dermatologia

An Bras D ermatol. 2015;90(4):561-3. 


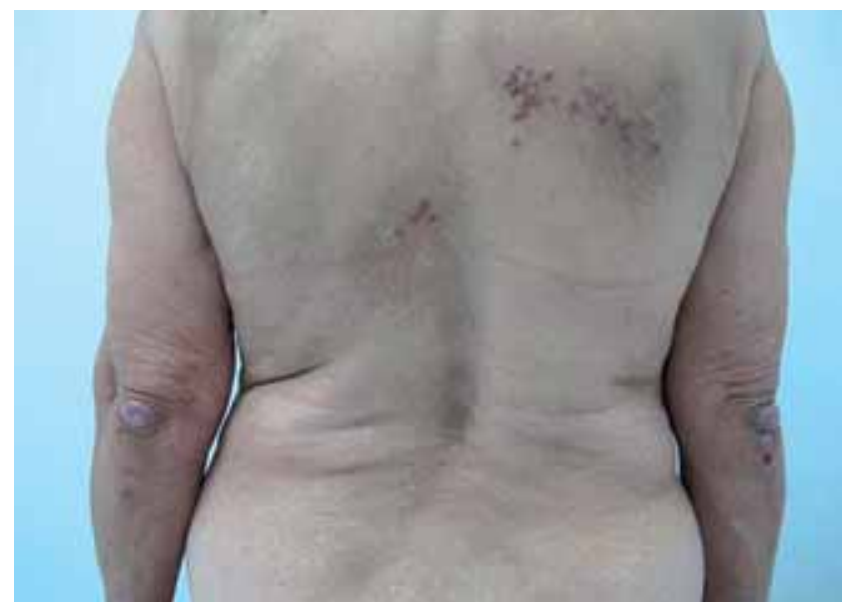

FIGURE 1: Erythematous violaceous papules grouped on the back and hardened symmetrical erythematous-violaceous nodules on the elbows

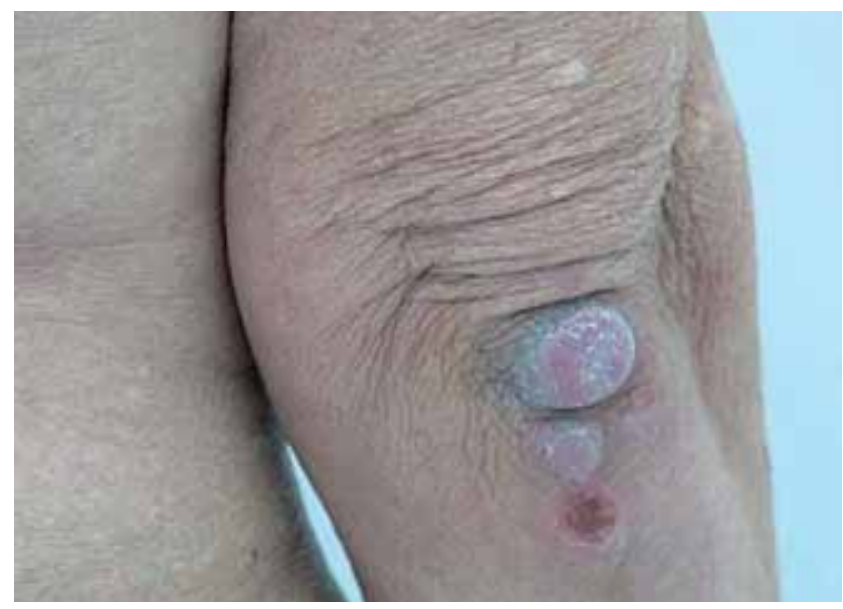

FIGURE 2: Hardened erythematous violaceous nodules and ulcerated nodule on the elbow

\section{DISQUSSION}

The EED is a rare, chronic leukocytoclastic vasculitis of unknown etiology. An association with hematologic diseases, such as monoclonal gamopathy, non-Hodgkin lymphoma, chronic lymphocytic leukemia and multiple myeloma; autoimmune diseases, such as rheumatoid arthritis, celiac disease, systemic lupus erythematosus, Sjögren syndrome, antiphospholipid antibody syndrome, pyoderma gangrenosum, diabetes mellitus type 1 and hypothyroidism; neoplastic diseases, as breast and lung cancer; and infectious diseases, as streptococcus infection, HIV and hepatitides. ${ }^{1-4}$ It is presumed that the pathogenesis is related to deposition of immune complexes on vessel walls, activation of the complement cascade, neutrophil chemotaxis, excessive premature expression of proinflammatory cytokines, releasing lysozymes, collagenase, myeloperoxidase

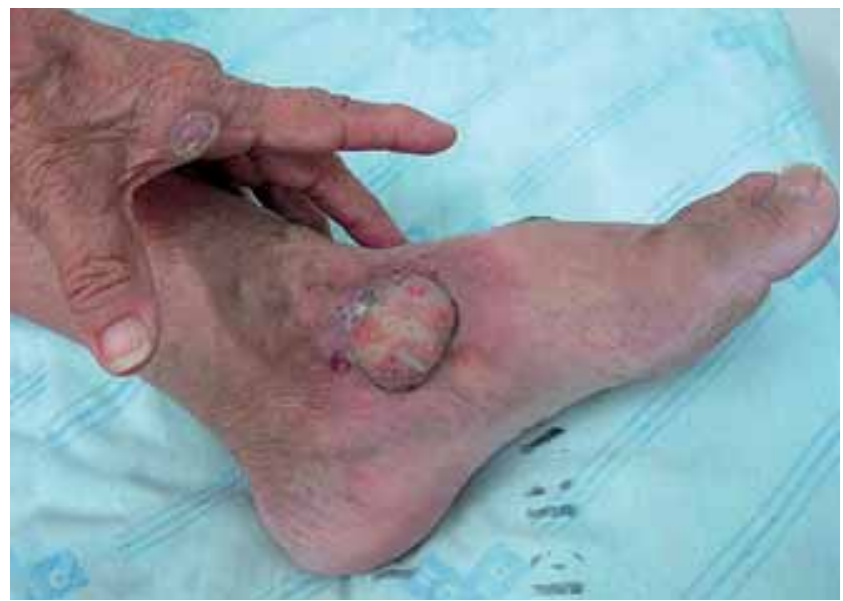

Figure 3: Ulcerated malleolar tumoral lesion and erythematous violaceous nodule on the lateral border of hand

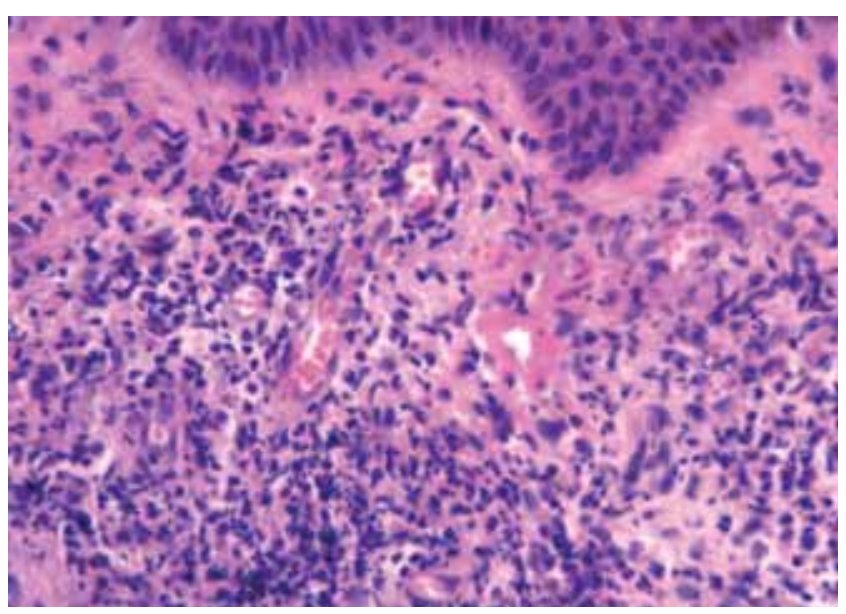

FIGURE 4: Vascular damage characterized by fibrinoid alterations and interstitial polymorphonuclear infiltrate on capillary walls

and hydrolases that induce deposition of fibrin inside and around the vessels. ${ }^{3,5,6,7}$ It is clinically manifested by erythematous violaceous papules and nodules, isolated or confluent in plaques, of hardened consistency; at first they are soft, gradually becoming hardened and symmetrical, predominantly on the extensor surface of the extremities, mainly over the joints of hands, elbows, knees and ankles. Lesions have already been described on the trunk and retroauricular region. ${ }^{2}$ There are atypical forms of presentation with vesicles, ulcers and hemorrhagic nodules. ${ }^{2}$ The partial resolution may impart a yellowish or brownish tone to the lesions, which take on the appearance of xanthomas. The lesions may resolve without scars or result in atrophy and depigmentation. The clinical picture is usually asymptomatic, but in some cases, the onset of lesions is associated with itching and burning 
sensations. ${ }^{1}$ Arthralgia and fever may be present. In cases associated with infection by HIV, the lesions are predominantly nodular and there is a palmoplantar involvement. ${ }^{2}$ The diagnosis is based on these clinical findings and on the histological picture that revealed leukocytoclastic vasculitis with neutrophilic infiltrate and fibrin deposit on the walls of small dermal vessels. In the beginning stage, polymorphonuclear infiltrate, macrophages, histiocytes and, more rarely, eosinophils may be found in perivascular sites. During the disease progression, histiocytes become proportionally the majority in the inflammatory infiltrate. Older lesions reveal a combination of granulation response and skin healing, with dermal proliferation of fusiform cells, associated or not to multinucleated giant cells. Vascular damage is demonstrated by the presence of dilated blood vessels with hypertrophic endothelial cells, projected to the lumen of the vessel. ${ }^{2}$ The differential diagnosis of EED is quite wide and includes Sweet Syndrome, pyoderma gangrenosum, facial granuloma, fixed drug eruption, erythema multiforme, bullous pemphigoid, porphyria cutanea tarda, multicentric reticulohistiocytosis, rheumatoid nodules, dermatofibroma, bacillary angiomatosis, Kaposi sarcoma and xanthoma. EED is a chronic disease, with relapses, making its treatment difficult. The drug of first choice is dapsone, for its inhibitory effect on the chemotaxis of neutrophils, but it is common for the patient to experience recurrence of lesions after the end of treatment and it seems less effective on fibrotic lesions. ${ }^{2}$ In these cases, the association of dapsone and surgical excision showed good results. ${ }^{6}$ Other therapeutic options described in the literature include nicotinamide, tetracycline, colchicine, niacinamide, chloroquine and cyclosporine. ${ }^{1,2,3}$ The use of cyclosporine in association with dapsone seems to have an additive or synergistic effect and may be an alternative for recalcitrant cases. ${ }^{8}$ High potency and intralesional topical corticoids may be very effective to reduce lesion size and are the treatment of choice for localized cases. ${ }^{5}$ In positive HIV patients, the association with the antiretroviral therapy seems to be effective. ${ }^{2,9}$ A typical case is reported, from the anatomo-clinical point of view, of EED associated with hypothyroidism, corroborating a report in the literature of Hashimoto thyroiditis as a possible autoimmune disease related to EED. ${ }^{10}$ As regards neoplasms, complete regression of cutaneous lesions has already been reported after treatment, and some authors suggest that the erythema elevatum diutinum is a paraneoplastic syndrome that may even precede by years hematologic malignancies. ${ }^{4}$ Therefore, medical follow-up is extremely important to outwit possible neoplasms. When an association with another disease is established, it should be treated. Although having a chronic and persistent character, some cases spontaneously in a five to ten-year period. ${ }^{4} \square$

\section{REFERENCES}

1. Lorenz AM, Garlatti Ml, Romano MS, Bollea L, Anzorena J. Erythema Elevatum Diutinum. Rev Argent Dermatol 2007;88:82-7.

2. Gibson LE, el-Azhary RA. Erythema elevatum diutinum. Clin Dermatol. 2000;18:295-9

3. Antonio JR, Antonio CR, Balau JP, Miguel D, Avila SCG. Erythema elevatum diutinum: a case report and review of the literature. An Bras Dermatol 2002;77:481-7.

4. Yilmaz F, Artac M, Ciftçioglu MA, Yilmaz E. A case of erythema elevatum diutinum associated with breast carcinoma. Int J Dermatol. 2005;44:948-50.

5. Costa FB, Duquia RP, Souza PR, Vettorato G, Almeida HL Jr. Case for diagnosis. Erythema elevatum diutinum. An Bras Dermatol 2009;84:429-30.

6. Zacaron LH, Gonçalves JC, Curty VM, D'Acri AM, Lima RB, Martins CJ. Clinical and surgical therapeutic approach in Erythema Elevatum Diutinum - Case report. An Bras Dermatol. 2013;88:15-8.

7. Caucanas M1, Heylen A, Rolland F, Müller G, Olemans C, Sass U, et al. Associated pyoderma gangrenosum, erythema elevatum diutinum, and Sweet's syndrome: the concept of neutrophilic disease. Int J Dermatol. 2013;52:1185-8.

8. Takahashi H, Fukami Y, Honma M, Ishida-Yamamoto A, lizuka H. Successful combination therapy with dapsone and cyclosporine for erythema elevatum diutinum with unusual appearance. J Dermatol. 2012;39:486-7.

9. Rover PA, Bittencourt C, Discacciati MP, Zaniboni MC, Arruda LH, Cintra ML. Erythema elevatum diutinum as a first clinical manifestation for diagnosing HIV infection: case history. Sao Paulo Med J. 2005:123:201-3.

10. Yamamoto T, Nakamura S, Nishioka K. Erythema elevatum diutinum associated with Hashimoto's thyroiditis and antiphospholipid antibodies. I Am Acad Dermatol. 2005;52:165-6.

\author{
M AILING ADDRESS: \\ Beatriz Lopes Ferraz Elias \\ A venida Granadeiro Guimarães, 270 \\ Centro \\ 12020-130 Taubaté, SP. \\ E-mail: beatrizelias@ig.com.br
}

How to cite this article: Cirvidiu DC, Elias BLF, Jorge JCF, Lira MLA, Mandelbaum SH. Erythema elevatum diutinum and hypothyroidism: coincidence or causal relationship? An Bras Dermatol. 2015;90(4):561-3. 